\title{
Karstik Bölge Akarsularında Taban Akışının Ayrılması
}

\author{
Baseflow Separation in Karstic Region Streams
}

\author{
Ebru ERIŞ
}

Ege Üniversitesi, Inşaat Mühendisliği Bölümü, Bornova, İZMiR

\section{ÖZ}

Taban akışının tahmini; su temini, sulama, akarsu taşımacıllğı, enerji üretimi ve yeraltı suyu çalışmaları vb. hidrolojik faaliyetler için önemlidir. Bu çalışmada, taban akışının tahminine yönelik literatürde kabul görmüş farklı yöntemler karstik özelliğe sahip Akdeniz Bölgesi akarsularına uygulanmıştır. Doğrusal Olmayan Hazne Yöntemi, İngiliz Hidroloji Enstitüsü Yöntemi ve Dijital Filtreleme Yöntemi havzadaki akım gözlem istasyonlarına ait günlük akımlara uygulanarak sonuçlar karşıllaştırılmıştır. Uygulanan yöntemlerin taban akış miktarını uygulama alanı ile ilgili mevcut çalışmalarda belirlenen taban akışına yakın tahmin ettiği görülmüş; uygulanan yöntemler arasında önceki çalışmalara en yakın sonuçların Doğrusal Olmayan Hazne Yöntemi ile elde edildiği saptanmıştır.

Anahtar Kelimeler: Akdeniz Bölgesi, Dijital Filtreleme Yöntemi, Doğrusal Olmayan Hazne Yöntemi, İngiliz Hidroloji Enstitüsü Yöntemi, Karstik Bölge, Taban Akışı.

\begin{abstract}
Baseflow estimation is important for hydrological activities such as water supply, irrigation, river transportation, energy production and groundwater practice. In this study, different methods widely used in the literature for baseflow estimation are applied on streams in the karstic Mediterranean Region. Three methods, the nonlinear baseflow separation, United Kingdom Institute of Hydrology and Recursive Digital Filter, were performed on daily flows of gauging stations in the region and results were compared. It is seen that the calculated baseflow is not far from results of previous case studies available for the study area. However, the nonlinear baseflow separation method is found to be the closest in terms of approaching the results of the previous studies.
\end{abstract}

Keywords: Mediterranean Region, Digital Filter Method, Nonlinear Baseflow Separation Method, United Kingdom Institute of Hydrology Method, Karstic Region, Baseflow. 


\section{GİRIŞ}

Akarsudaki toplam akış dolaysız ve dolaylı olmak üzere iki ana bileşene ayrılabilir. Dolaysız (doğrudan) akış, yüzey akışı ve yüzeyaltı akışının gecikmeyen kısmı; dolaylı akış ise yeraltı akışı ile yüzeyaltı akışının gecikmeye uğramış kısmı olan taban akışı olarak tanımlanmaktadır. Dolaysız akış ancak yağış şiddetinin zeminin sızma kapasitesini aştığı zamanlarda meydana geldiği için şiddetli yağışlardan sonra önem kazanmaktadır. Yağışsız kurak dönemlerde akarsuyu besleyen en önemli kaynak taban akışı olduğundan taban akışının önemi özellikle kurak dönemlerde ortaya çıkar.

Taban akışının tahmini, hidroloji ve su kaynaklarını ilgilendiren pek çok konu ile doğrudan ilişkilidir. Bu amaçla yapılan yağışakış modelleri, hidrograf analizi, düşük akım istatistikleri, havza depolama kapasitesi tahmini gibi hidrolojik ve su kaynakları ile ilgili çalışmalarda taban akışının belirlenmesi gereklidir.

Taban akışının belirlenmesi için çeşitli yöntemler bulunmaktadır. Bunlardan teknolojik izleme yöntemleri masraflıdır. Taban akışını ayırmada kimyasal izleyiciler ve saha çalışma ve gözlemleri gibi yöntemler geniş havzalarda uygulanamamaktadır. $\mathrm{Bu}$ yüzden hidrograf analizine dayanan taban akışı ayırma yöntemleri geliştirilmiştir. Dünyada olduğu gibi Türkiye'de de henüz genel kabul görmüş bir taban akışı ayırma yöntemi bulunmadığından uygulamada basit ancak son derece öznel grafik yöntemlerle yetinilmektedir. $\mathrm{Bu}$ yöntemlerin her biri diğerinden farklı sonuçlar verebilmektedir.

Grafik yaklaşımların (Hall, 1971; Chapman, 1999) yanında konu ile ilgili analitik (Birtles, 1978; Szilagyi ve Parlange, 1998) veya sayısal modeller de (Nathan ve McMahon, 1990; Arnold vd., 1995) geliştirilmiştir. Grafik yaklaşımlar içerisinde yeraltı suyu biriktirme sisteminin doğrusal bir hazne olduğu kabulü üzerine kurulmuş çok sayıda yöntem bulunmakla birlikte doğrusal olmayan hazne kabulüne dayanan yöntemler de bulunmaktadır. Doğrusal Olmayan Hazne Yöntemi'nin (DOHY) Türkiye'de uygulamaları mevcuttur (Wittenberg ve Aksoy, 2010; Aksoy ve Wittenberg, 2011, 2015; Eris ve Wittenberg, 2015). Sayısal yöntemlerden İngiliz Hidroloji Enstitüsü Yöntemi (İHEY) ve Dijital Filtreleme Yöntemi (DFY) ise yine taban akışı ayırmada kullanılmaktadır. İHEY adında anlaşılacağ1 üzere İngiliz Hidroloji Enstitüsü tarafından önerilmiş (IH, 1980) ve Piggott vd. (2005) tarafından revize edilmiştir. DFY ise Lyne ve Hollick (1979) tarafindan önerilen algoritmanın günlük akım verilerine uygulanması ile geliştirilmiştir (Nathan ve McMahon, 1990; Eckhart, 2005; Li vd., 2014; Su vd., 2016). Sayısal yöntemler ve regresyon denklemleri ile taban akışı tahmini ülkemiz akarsuları için de gerçekleştirilmiştir (Kurt, 2007; Aksoy vd., 2008; Saplığlu ve Çimen, 2010; Zaifoğlu, 2013; Kayan, 2014).

Öte yandan, Türkiye akarsu havzalarının üçte birinin karstik bölgelerde bulunduğu bilinmektedir (Benzeden vd., 1993; Graf ve Bozcu, 2006). Mevcut su kaynaklarının önemli bir kısmının bu akarsu havzaları üzerinde bulunduğu dikkate alındığında, özellikle karstik pınar boşalımlarının önem taşıdığ akarsu havzalarında yapılacak planlamalarda taban akıșının doğru olarak belirlenmesinin önemi anlaşılabilir. Bu çalışma için seçilen ve karstik yapıya sahip bölgelerimizden biri olan Akdeniz Bölgesi akarsularında da çekilme eğrisi parametrelerinin ve yeraltı suyu miktarının belirlenmesi için çeşitli çalışmalar yapılmıştır (Ünal, 1981; Baran ve Harmancioğlu, 1993; Saplığlu, 2005; Koç, 2008). 
$\mathrm{Bu}$ çalışmada, DOHY, İHEY ve DFY karstik yapıya sahip Akdeniz Bölgesindeki akarsulara uygulanmıştır. Çalışmanın temel amacı söz konusu yöntemlerin karstik bölgelere uygulanabilirliğin araştırılması, farklı yöntemlerle elde edilen taban akışı ve buna bağlı olarak yüzeysel akışa karst katkı miktarlarının belirlenmesi ve mevsimsel değişimlerinin karşılaştırılmasıdır.

\section{YÖNTEMLER}

\section{Doğrusal Olmayan Hazne Yöntemi (DOHY)}

Havzadaki biriktirme sisteminin doğrusal bir hazne olduğu kabulü üzerine kurulmuş çok sayıda yöntemin yanı sıra, söz konusu sistemin doğrusal olmayan yapısını dikkate alarak taban akışını toplam akıştan ayıran bir yöntem de mevcuttur. Wittenberg (1999) tarafindan geliştirilen ve Wittenberg ve Sivapalan (1999), Wittenberg (2003), Wittenberg ve Aksoy (2010), Aksoy ve Wittenberg $(2011,2015)$ tarafından da kullanılan yöntemin esası aşağıda verilmektedir.

Doğrusal olmayan hazne teorisinde, depolama hacmi $(S)$; debi $(Q)$ ile,

$S=a Q^{b}$

şeklinde ilişkilendirilmiştir. Hazneye girdi olmadığında (havzaya yağış düşmediğinde) süreklilik denklemi

$\frac{d S}{d t}=-Q$

şeklindedir. (1) ve (2) eşitliklerinin birleştirilmesi ile elde edilen diferansiyel denklemin $Q_{0}$ başlangıç koşulu göz önünde bulundurularak yapılan çözümü

$Q_{t}=Q_{0}\left[1+\frac{(1-b) Q_{0}{ }^{1-b}}{a b} t\right]^{\frac{1}{b-1}}$

olarak bulunur. (3) eşitliğinde geçen $a$ ve $b$ parametreleri gözlenen günlük akım verileri kullanılarak ayarlanır (kalibre edilir). Yapılan çok sayıda uygulama sonrasında $b=0.5$ alınabileceği sonucuna ulaşı1mış, serbest yüzeyli akiferler için $b=0.5$ 'in standart bir üs olarak kullanılabileceği, $a$ 'nın ise zeminin boşluk oranı, hidrolik iletkenliği ve diğer morfometrik özellikleri ile ilgili bir parametre olabileceği düşünülmüştür. Nitekim bu çalışmada da $b$ parametresi sabit kabul edilerek her bir ay için $a$ parametreleri belirlenmiştir. $\mathrm{Bu}$ işlem sırasında hesaplanan ve gözlenen çekilme eğrileri arasındaki benzerliğin kriteri olarak varyasyon katsayısı kullanılmıştır. Varyasyon katsayıs1;

$C V=\frac{1}{\overline{Q_{\text {gözlem }}}} \sqrt{\frac{\sum_{i=1}^{N}\left(Q_{i, \text { gözlem }}-Q_{i, \text { tah } \min }\right)^{2}}{N-1}}$

ile hesaplanmıştır. Burada $Q_{\text {gözlem }}, Q_{\text {tahmin }}$ sırasıyla gözlenen ve tahmin edilen akım değerlerini; $N$ çekilme eğrisindeki gün sayısını göstermektedir. Çekilme parametreleri belirlendikten sonra her bir istasyon için taban akışı BNLP adı verilen bir FORTRAN programı (Wittenberg, 1999) ile toplam akıştan ayrılmıştır.

\section{İngiliz Hidroloji Enstitüsü Yöntemi (İHEY)}

Taban akışını toplam akıştan ayırmak için kullanılan dijital filtreleme tekniklerinden biri olan İHEY İngiliz Hidroloji Enstitüsü tarafından önerilmiştir (İH, 1980). Yöntem, $0.9 y_{i} \leq \min \left(y_{i-1}, y_{i+1}\right)$ günlük akım gözlem serilerinin dönüm noktalarının belirlenmesi ve bu noktalar arasındaki doğrusal enterpolasyona dayanmaktadır. Birbirleriyle çakışmayacak şekilde günlük akımlar beşer günlük gruplara ayrılır ve bu grupların minimumları belirlenir. Yöntemde sağlandığ minimum ( $y$ ) dönüm noktası olarak kabul edilir. Yöntemde kullanılan 0.9 katsayısı kesin 
bir katsayı olmamakla birlikte bu çalışmada değiştirilmeden kullanılmıştır. Dönüm noktaları belirlendikten sonra, söz konusu noktalar doğrusal enterpolasyon ile birleştirilerek taban akışını temsil eden bir zaman serisi elde edilir.

\section{Dijital Filtreleme Yöntemi (DFY)}

$\mathrm{Bu}$ yöntemde, toplam akışın taban akışı ve yüzey akışını içeren iki bölümden oluştuğu kabul edilir (Nathan ve McMahon, 1990). Yöntemde taban akış1,

$f_{t}=\alpha f_{t-1}+\frac{(1+\alpha)}{2}\left(y_{t}-y_{t-1}\right)$

ile ayrılır. Burada $f_{t}, t$ zamanındaki filtre edilmiş yüzey akışı $y_{t}, t$ zamanındaki günlük akım, $a$ ise filtre parametresidir. Buna göre taban akışı;

$b_{t}=y_{t}-f_{t}$

şeklinde elde edilebilir. Filtre parametresi için en uygun değer Nathan ve McMahon (1990) tarafindan 0.925 olarak verilmiş ve bu çalışmada aynen kullanılmıştır. Taban akışı ileri, geri ve tekrar ileri olmak üzere üç kez yapılan filtreleme sonucu elde edilmiştir.

\section{ÇALIŞMA ALANI VE VERİ}

Çalışma alanı karstik yapıya sahip Akdeniz Bölgesi'dir. Kışın ılık ve yağışlı, yazın kurak ve sıcak iklime sahip Akdeniz Bölgesi'nde nadiren kar yağışı görülmektedir. Şekil 1'den anlaşılacağ1 üzere bölgenin iç kesimi kıyı kesimlerine göre daha az yağış almaktadır. Antalya, Muğla, Isparta ve Burdur verilerine dayanarak bölgenin yıllık toplam yağış ortalaması yaklaşık $420 \mathrm{~mm}$ ile $1160 \mathrm{~mm}$ arasında değişmektedir. Bölgenin sıcaklık ortalaması ise $15^{\circ} \mathrm{C}$ 'dir (MGM, 2015).

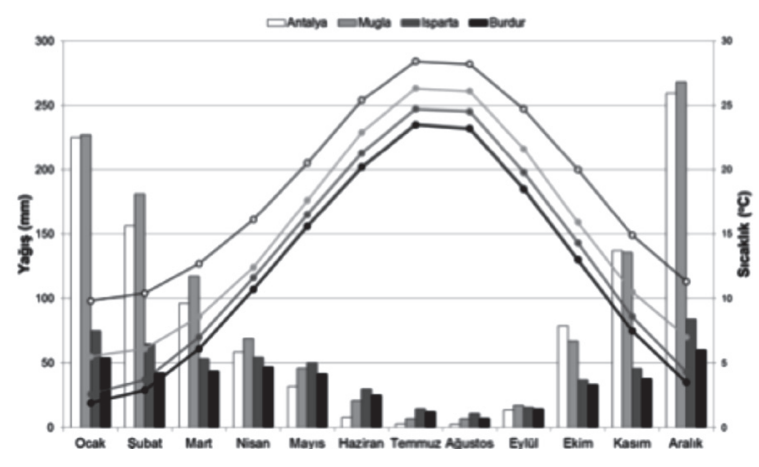

Şekil 1. Çalışma alanına ait uzun yıllar (1954-2013) için yıllık toplam yağış ve sıcaklık ortalaması.

Figure 1. Mean total precipitation and temperature of the study area for long-term (1954-2013).

Taban akışının belirlenmesinde bölgedeki üç Akım Gözlem İstasyonu'na (AGİ) ait günlük akım verileri kullanılmıştır. İstasyonların konumları Şekil 2'de, ve istasyonlara ait genel özellikler Çizelge 1'de verilmiştir. Bu istasyonların ikisi Manavgat Nehri, diğeri ise Köprüçay üzerinde bulunmaktadır.

Manavgat Nehri ortalama akımının yaklaşı üçte ikisinin karstik pınarlardan geldiği, nehir üzerinde bulunan Oymapınar Baraj Gölü altında kalan Dumanlı Pınarı'nın ortalama akımının 50 $\mathrm{m}^{3} / \mathrm{s}$ olduğu, Dumanlı dişında kalan ve debileri $1-10 \mathrm{~m}^{3} / \mathrm{s}$ arasında değișen 40 kadar pınarın nehri beslediği bilinmektedir (Öziş ve Keloğlu, 1979; Karanjac ve Günay, 1980). Köprüçay üzerinde ise Bolasan AGI'sinin mansabında kalan Olukköprü kaynağı başta olmak üzere irili ufaklı pek çok karstik kaynak mevcuttur (Değirmenci, 1989). Çekilme eğrilerinin belirlenmesinde ayrıca civardaki yağış gözlem istasyonlarının günlük yağış verileri kullanılmıştır. 
Çizelge 1. Çalışmada kullanılan akım gözlem istasyonlarına ait genel özellikler.

Table 1. General characteristics of flow gauging stations used in the study.

\begin{tabular}{cccc}
\hline $\begin{array}{c}\text { İstasyon No } \\
\text { İstasyon Adı }\end{array}$ & $\begin{array}{c}\text { E09A012 } \\
\text { Sinanhoca } \\
\text { (Manavgat N.) }\end{array}$ & $\begin{array}{c}\text { E09A019 } \\
\text { Bolasan } \\
\text { (Köprüçay) }\end{array}$ & $\begin{array}{c}\text { E09A020 } \\
\text { Şahapköprü } \\
\text { (Manavgat N.) }\end{array}$ \\
\hline Enlem & $31^{\circ} 36^{\prime} 31^{\prime \prime} \mathrm{D}$ & $31^{\circ} 11^{\prime} 23^{\prime \prime} \mathrm{D}$ & $31^{\circ} 39^{\prime} 29^{\prime \prime} \mathrm{D}$ \\
Boylam & $36^{\circ} 58^{\prime} 46^{\prime \prime} \mathrm{K}$ & $37^{\circ} 18^{\prime} 15^{\prime \prime} \mathrm{K}$ & $3^{\circ} 4^{\prime} 28^{\prime \prime} \mathrm{K}$ \\
Drenaj Alanı (km²) & 625.6 & 1538.4 & 438 \\
Yükseklik (m) & 245 & 435 & 432 \\
Gözlem süresi & $10.1963-09.2013$ & $10.1984-09.2009$ & $10.1991-09.2012$ \\
Ort. Akım (m³) & 70.5 & 22.9 & 19.3 \\
Kuru gün sayısi & 608 & 332 & 566 \\
(Gözlem süresi içinde) & & & \\
\hline
\end{tabular}

\section{UYGULAMA}

Taban akışını ayırmada; DOHY, İHEY ve DFY yöntemleri kullanılmıştır. DOHY; doğrusal olmayan hazne teorisini kullanmakta; günlük akım verilerinden elde edilen çekilme eğrisinin parametrelerini akımın periyodikliğine bağlı olarak hesaplamaktadır. Buna göre çalışma alanına ait günlük akım verileri kullanılarak her bir aya ait çekilme eğrileri belirlenmiştir. Çekilme eğrileri seçiminde yağışsız dönemler göz önüne alınmıştır. Bu nedenle akım gözlem istasyonlarına ait hidrograflar civardaki yağış istasyonlarının günlük yă̆gş verileri ile karşılaştırılmıştır. Çekilme eğrisinin en az 5 gün boyunca devam etmesi öngörülmüştür. Bir sonraki aya (aylara) uzayan çekilme eğrileri çekilmenin başladığı aya ait sayılmış, böylece her bir ayı temsil edecek nitelikte çekilme eğrileri belirlenmiştir.

Çekilme eğrileri belirlendikten sonra çekilme parametresi $b=0.5$ sabit alınarak, her bir çekilme eğrisi için $a$ parametresi kalibre edilmiştir. Varyasyon katsayısı \%10'dan büyük olmayacak şekilde kalibrasyon yapılmıştır (Eris ve Wittenberg, 2015). Çekilme parametresi belirlendikten sonra BNLP adlı FORTRAN program1 (Wittenberg, 1999; Wittenberg ve Sivapalan, 1999) yardımıyla taban akışı her bir istasyon için ayrılmıştır.

İHEY yöntemi çerçevesinde öncellikle çalışma bölgesindeki AGI'lerin günlük akımları beşerli gruplara ayrılmış, her gruba ait minimum değerler ve dönüm noktaları belirlenmiştir. Dönüm noktaları doğrusal enterpolasyon ile birbirine bağlanarak toplam akıştan taban akışı ayrılmıştır. DFY yöntemiyle günlük akım verileri ileri-geri-ileri olmak üzere üç kez filtre edilerek taban akışı toplam akıştan ayrılmıştır.

Buna göre, Bolasan, Şahapköprü ve Sinanhoca havzaları için toplam akış ve taban akışı ayırma yöntemlerine göre belirlenen taban akışı grafikleri örnek olmak üzere Şekil 3'te sunulmuştur. 
Eriş

(a)
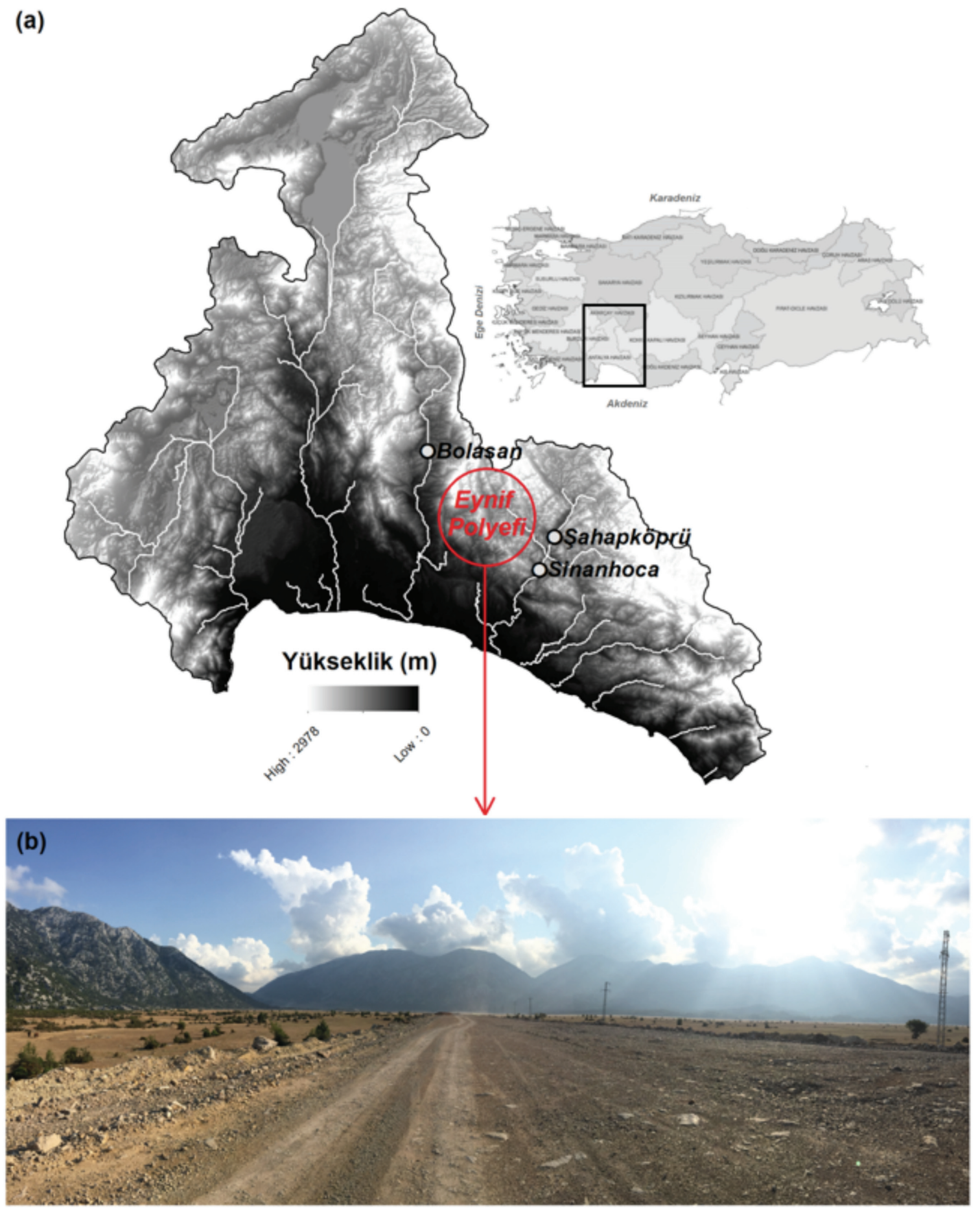

Şekil 2. (a) Çalışma alanı ve AGİ'lerin konumları, (b) Eynif Polyesi.

Figure 2. (a) Study area and locations of the flow gauging stations, (b) Eynif Polje. 
Ayrıca aylık toplam akış ile hesaplanan aylık taban akışı miktarları Şekil 4'te görülmektedir. Farkl1 yöntemlere göre belirlenen taban akışlarının aylık değişimleri birbirine benzemekle birlikte her üç istasyon için DOHY ile bulunan taban akışı miktarları diğerlerine göre daha büyük sonuçlar vermektedir. Tüm yöntemler için taban akışı değerleri kış aylarında yükselmeye başlamakta, sonbaharda ise minimum değerlerine ulaşmaktadır. Bolasan ve Şahapköprü AGI'leri için minimum akımlar Ağustos-Eylül aylarında görülürken (Şekil 4a ve b) Sinanhoca AGI'si için minimum taban akışları Ekim ortasında görülmektedir. Aylık toplam akış ve taban akışlarında görülen bu kayma günlük akım ve taban akışı grafiklerinde de fark edilmektedir (Şekil 3).

Bu üç AGI'ye ait 1992-2008 ortak gözlem dönemi göz önüne alınarak aylık toplam akış, taban akışı ve doğrudan akım değerleri; taban akışının toplam akışa oranları ile birlikte hesaplanmış ve Çizelge 2'de sunulmuştur. Çizelge 2'den görüldüğü üzere her üç yöntem sonucunda bulunan taban akışı miktarları toplam akışın büyük bir kısmını oluşturmaktadır. Taban akışının toplam akışa oranı özellikle Sinanhoca AGI'sinde DOHY, İHEY ve DFY'ye göre sırasıyla \% 88, 74 ve 63'e kadar ulaşmıştır. $\mathrm{Bu}$ oran Şahapköprü ve Bolasan istasyonları için daha düşük olarak tayin edilmiştir. Aylık taban akış miktarlarında görülen durum Çizelge 2'den de görülmektedir. Yani DOHY ile bulunan taban akışları diğer yöntemlere göre daha büyük orandadır. Bu durum aslında DOHY'de esas alınan taban akışı tanımından ileri gelmektedir. Bu yöntemde yalnızca yeraltı suyu değil yüzey altı akışı da taban akışı içinde değerlendirilmektedir.

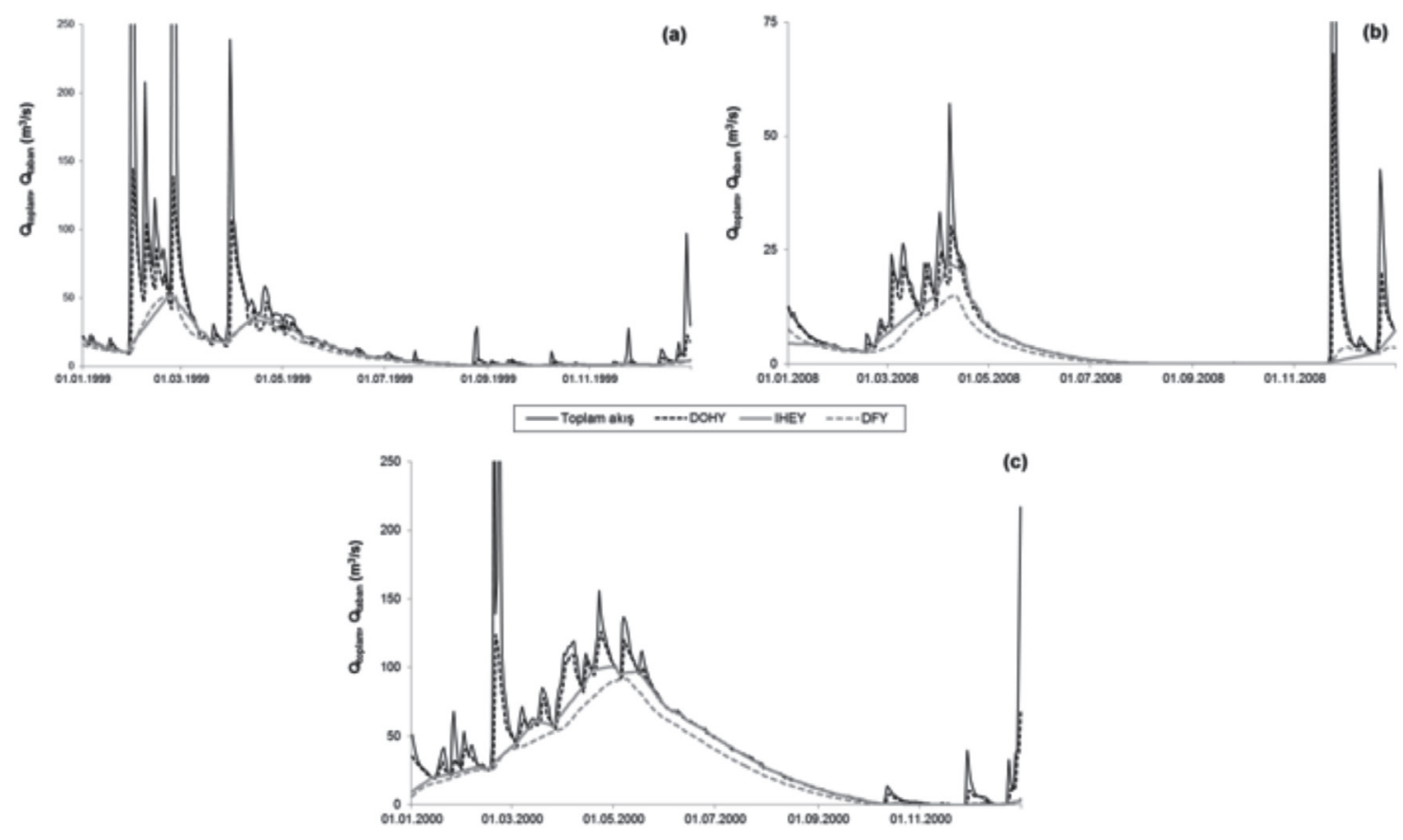

Şekil 3. AGI'lere ait örnek günlük toplam akım ve farklı yöntemlere göre belirlenmiş taban akışı değerleri; (a) Bolasan, (b) Şahapköprü, (c) Sinanhoca.

Figure 3. Daily total flow and baseflow determined by different methods for (a) Bolasan, (b) Şahapköprü, (c) Sinanhoca. 
Çizelge 2. AGI'ler için toplam, doğrudan, taban akışı değerleri ve taban akışının toplam akışa oranı.

Table 2. Total, direct and base flows, and ratio of baseflow to total flow for the flow gauging stations.

\begin{tabular}{|c|c|c|c|c|c|c|c|c|c|c|}
\hline \multicolumn{2}{|c|}{$\begin{array}{c}\text { Taban Akışı Ayırma } \\
\text { Yöntemi }\end{array}$} & \multicolumn{3}{|c|}{ DOHY } & \multicolumn{3}{|c|}{ İHEY } & \multicolumn{3}{|c|}{ DFY } \\
\hline \multirow[t]{2}{*}{ İstasyon } & $V_{\text {toplam }}$ & $V_{\text {doğrudan }}$ & $V_{\text {taban }}$ & $\begin{array}{l}V_{\text {taban }} / \\
V_{\text {toplam }} \\
\end{array}$ & $V_{\text {doğrrudan }}$ & $V_{\text {taban }}$ & $\begin{array}{l}V_{\text {taban }} / \\
V_{\text {toplam }}\end{array}$ & $V_{\text {doğrudan }}$ & $V_{\text {taban }}$ & $\begin{array}{l}V_{\text {taban }} / \\
V_{\text {toplam }}\end{array}$ \\
\hline & \multicolumn{3}{|c|}{$\left(10^{6} \mathrm{~m}^{3}\right)$} & $(\%)$ & \multicolumn{2}{|c|}{$\left(10^{6} \mathrm{~m}^{3}\right)$} & $(\%)$ & \multicolumn{2}{|c|}{$\left(10^{6} \mathrm{~m}^{3}\right)$} & $(\%)$ \\
\hline $\begin{array}{c}\text { Bolasan } \\
\text { (Köprüçay) }\end{array}$ & 723 & 233 & 490 & 68 & 390 & 333 & 46 & 431 & 292 & 40 \\
\hline $\begin{array}{l}\text { Şahapköprü } \\
\text { (Manavgat N.) }\end{array}$ & 554 & 151 & 404 & 73 & 245 & 299 & 54 & 303 & 251 & 45 \\
\hline $\begin{array}{c}\text { Sinanhoca } \\
\text { (Manavgat N.) }\end{array}$ & 1964 & 244 & 1720 & 88 & 502 & 1462 & 74 & 731 & 1233 & 63 \\
\hline
\end{tabular}

Öziş ve Keloğlu (1979) Manavgat havzası için yaptıkları çalışmada, Manavgat nehri akımının \% 80-85'inin karst yeraltı suyu tarafından sağlandığını belirtmektedir. Baran vd. (1987), Türkiye'de karst pınar katkıları üzerine yaptıkları çalışmada ise Sinanhoca, Şahapkörü ve Bolasan AGI'leri için pınar katkısının 65, 18 ve $22 \mathrm{~m}^{3} / \mathrm{s}$ olduğunu bulmuşlardır. Bu değerler çalışmada göz önüne alınan gözlem süresindeki toplam akımın (yüzeysel ve taban akışı birlikte) sırasıyla yaklaşık \% 80, \% 70 ve \% 77'sine karşılık gelmektedir. Önceki çalışmalarda bulunan taban akışı oranları bu çalışmada kullanılan DOHY'e göre bulunan değerlere daha yakındır. DOHY'e göre taban akışının toplam akışa oranı (1992-2008 yılları arası) sırasılyla $\%$ 88, \% 73 ve \% 68 hesaplanmıştır. İHEY ve DFY'ye göre ise bu değerler çok daha düşüktür. $\mathrm{Bu}$ yönüyle DOHY'nin karstik bölgelerde kullanılabilirliğinden ve daha gerçekçi değerler verdiğinden bahsetmek mümkündür.

Önceki çalışmalar (Eris ve Wittenberg, 2015) karstik yapıya sahip çalışma alanında Manavgat Havzası'na doğru bölgenin kuzeyinden ve Bolasan Havzası'ndan (kuzeybatı) yeraltı suyu transferi olduğunu ve bu transferin özellikle Şahapköprü ve Sinanhoca AGI'leri arasında kalan kısımdan nehre katıldığını düşündürmektedir (Eynif Polyesi, Şekil 2b). Şekil 4'te sunulan aylık değişimler Bolasan ve Şahapköprü AGI'leri için minimum akımların Ağustos-Eylül aylarında, Sinanhoca için ise Ekim ortasında gerçekleştiğine işaret etmekle birlikte, Manavgat Nehri'nin özellikle kuzey ve kuzeybatısından geldiği düşünülen yeraltı suyunun gecikme süresinin yaklaşık 1-1.5 ay olduğu söylenebilir. 

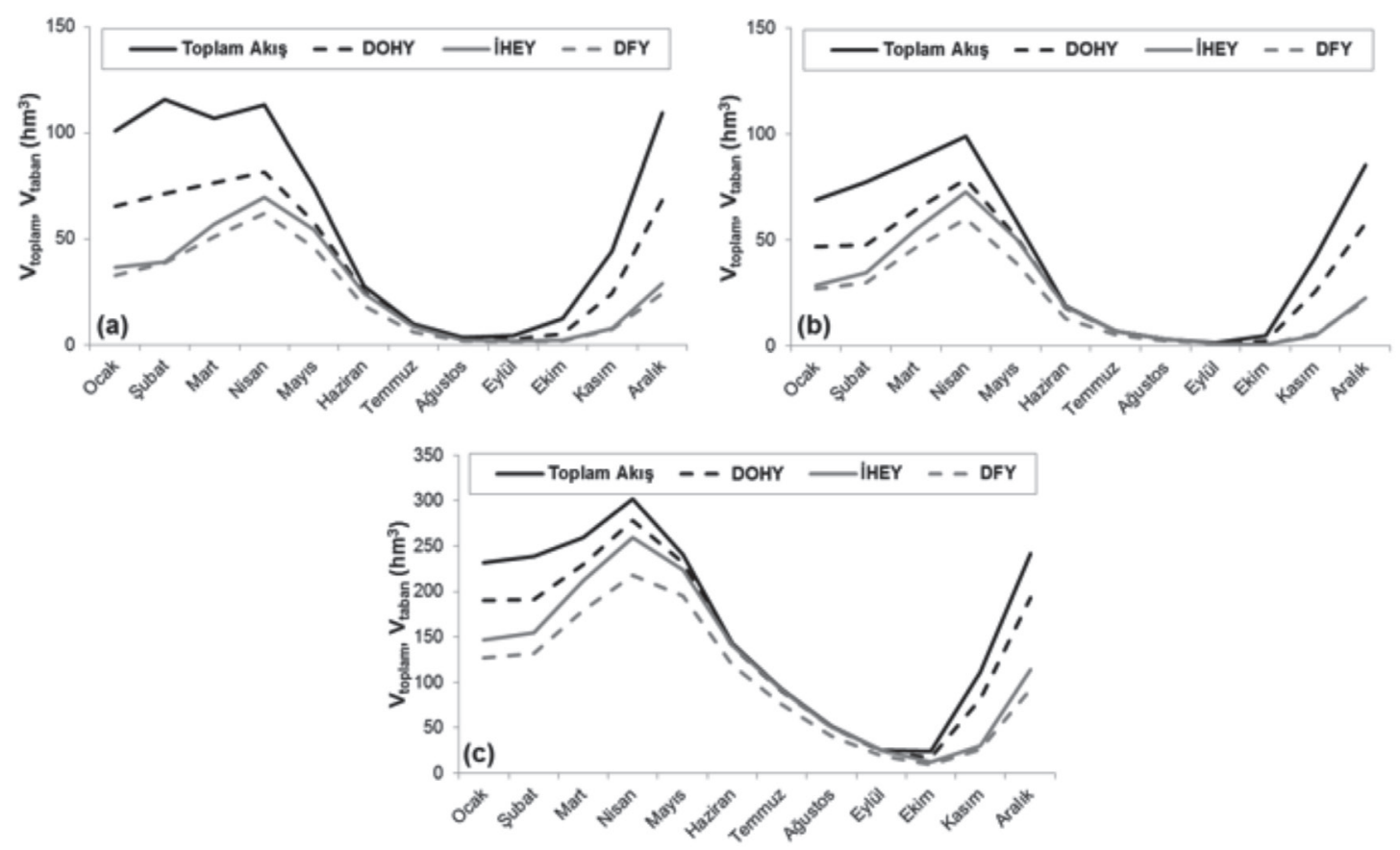

Şekil 4. Aylık toplam akış $\left(\mathrm{V}_{\text {toplam }}\right)$ ve taban akışı $\left(\mathrm{V}_{\text {taban }}\right)$ hacimleri; (a) Bolasan, (b) Şahapköprü, (c) Sinanhoca. Figure 4. Monthly total flow $\left(V_{\text {total }}\right)$ and baseflow $\left(V_{\text {base }}\right)$ volumes for $(a)$ Bolasan, (b) Şahapköprü, (c) Sinanhoca.

\section{SONUÇLAR}

Bu çalışmada, taban akışını toplam akıştan ayırmada farklı yöntemler kullanılmış ve birbirleriyle karşılaştırılmıştır. Daha önce gerek ülkemizdeki havzalarda gerekse diğer ülke havzalarında tecrübe edilmiş sayısal filtreleme teknikleri ile Doğrusal Olmayan Hazne Yöntemi taban akışını ayırmada kullanılmıştır. Söz konusu yöntemler, Türkiye'nin yaklaşık üçte birini kaplayan karstik bölge havzalarına uygulanmıştır. Çalışma alanı olarak özellikle Oymapınar Barajının yapımıyla birlikte 1970'li yıllardan beri pek çok çalışmaya konu olan Akdeniz Bölgesi karstik akarsuları seçilmiştir. Yapilan hesaplamalar sonucunda toplam taban akışının miktarının önceki çalışmalarda hesaplanan taban akışından çok uzak olmadığı görülmüştür. Bununla birlikte önceki çalışmalarla karşılaştırıldığında Doğrusal Olmayan Hazne Yöntemi'nin karstik bölgelerde daha tatminkâr sonuçlar verdiği düşünülmektedir. Doğrusal Olmayan Hazne Yöntemi'nin, İngiliz Hidroloji Enstitüsü Yöntemi ve Dijital Filtreleme Yöntemi'ne göre daha yüksek taban akışı oranları vermesi Doğrusal Olmayan Hazne Yöntemi'nin yeraltı suyu ile birlikte yüzeyaltı suyunu da göze almasından kaynaklanmaktadır.

Öncekiçalışmalardanfarklıolarakeldeedilen aylık değişimler incelendiğinde Şahapköprü ve Bolasan için minimum taban akışının AğustosEylül aylarında oluştuğu gözlenirken; Sinanhoca için minimum taban akışının Ekim ortasına kadar geciktiği görülmüştür. $\mathrm{Bu}$ gecikme; Sinanhoca havzasının, bölgenin karstik yapısı nedeniyle özellikle kuzeyden ve kuzeybatıdan (Eynif Polyesi'nden) beslendiğini düşündürmektedir. 
Sinanhoca yeraltı suyu drenaj alanının, Şahapköprü ve kuzeyi ile Bolasan havzasının bir kısmını kapsayacak şekilde, yerüstü drenaj alanından yaklaşık üç kat daha büyük olduğu tahmin edilmektedir.

\section{KATKI BELIRTME}

$\mathrm{Bu}$ çalışmanın bir bölümü TÜBİTAK'ın 2219-Yurt D1ş1 Doktora Sonrası Araştırma Burs Programı tarafindan desteklenmiştir. Yazar, makalenin gelişmesinde katkıda bulunan hakemlere teşekkür eder.

\section{KAYNAKLAR}

Aksoy, H., Unal, N. E., Pektas, A. O., 2008. Smoothed minima baseflow separation tool for perennial and intermittent streams. Hydrological Processes, 22, 4467-4476.

Aksoy, H., Wittenberg, H., 2011. Nonlinear baseflow recession analysis in watersheds with intermittent streamflow. Hydrological Sciences Journal, 56 (2), 226-237.

Aksoy, H., Wittenberg, H., 2015. Baseflow recession analysis for flood-prone Black Sea watersheds in Turkey. CLEAN - Soil, Air, Water, 43 (6), 857866.

Arnold, J. G., Allen, P. M., Muttiah, R., Bernhardt, G., 1995. Automated base flow separation and recession analysis techniques. Groundwater, 33 (6), 1010-1018.

Baran, T., Harmancioğlu, N. B., 1993. Assessment of mathematical models with exponential functions describing karstic spring discharges. UKAM, IAHS \& IAH, International Symposium and Field Seminar on Hydrogeologic Processes in Karst Terrains, Antalya, Turkey. (Editors: LaMoreaux, Assaad and McCorley) Hydrogeological Processes in Karst Terrains. IAHS Publ. No. 207, 231-241.

Baran, T., Harmancioğlu, N., Öziş, Ü., 1987. Türkiye'nin akarsularında karst pınar katkıları. Türkiye İnşaat Mühendisliği IX. Teknik Kongresi, 299-311.
Benzeden, E., Olcay, M. S., Bağalı, K., 1993. Flood frequency analysis in karst river basins, UKAM, IAHS \& IAH, International Symposium and Field Seminar on Hydrogeological Processes in Karst Terranes, Antalya, Turkey. (Editors: LaMoreaux, Assaad and McCorley). IAHS Publ. No. 207, 187-202.

Birtles, A.B., 1978. Identification and separation of major base flow components from a stream hydrograph. Water Resources Research. 14 (5), 791-803.

Chapman, T., 1999. A comparison of algorithms for stream flow recession and baseflow separation. Hydrological Processes, 13, 701-714.

Değirmenci, M., 1989. Köprüçay havzası ve dolayının (Antalya) karst hidrojeolojisi incelemesi. Hacettepe Üniversitesi Fen Bilimleri Enstitüsü, Ankara, Yüksek Lisans Tezi, 398 s (yayımlanmamış).

Eckhardt, K., 2005. How to construct recursive digital filters for baseflow separation. Hydrological Processes, 19, 507-515.

Eris, E., Wittenberg, W., 2015. Estimation of baseflow and water transfer in karst catchments in Mediterranean Turkey by nonlinear recession analysis. Journal of Hydrology, 530, 500-507.

Graf, İ. K., Bozcu, A., 2006. Yapısal özelliklerin lapya gelişimindeki rolü: Kızılörü Dağı doğusu (Korkuteli-Antalya). Jeoloji Mühendisliği Dergisi, 30, 9-16.

Hall, A. J., 1971. Baseflow recessions and baseflow hydrograph separation problem. Proceedings of the Hydrology Symposium, Institution of Engineers, Australia, Canberra, 159-170.

Institute of Hydrology (IH), 1980. Low flow studies research report. Institute of Hydrology Report $\mathrm{No}=1,50 \mathrm{p}$ (unpublished).

Karanjac, J., Günay, G., 1980. Dumanlı spring, Turkey-The largest karstic spring in the World? Journal of Hydrology, 45, 219-231.

Kayan, G., 2014. Sakarya ve Batı Karadeniz akarsu havzaları için taban akışı ayırma modeli. İstanbul Teknik Üniversitesi Fen Bilimleri Enstitüsü, İstanbul, Yüksek Lisans Tezi, $113 \mathrm{~s}$ (yayımlanmamış). 
Koç, A. C., 2008. Evaluation of karstic aquifers contribution to streams by the statistical analysis of recession curves. Journal of Earth System Science, 117 (1), 59-67.

Kurt, İ., 2007. Filtre edilmiş yuvarlatılmış minimumlar taban akışı ayırma yöntemi. İstanbul Teknik Üniversitesi Fen Bilimleri Enstitüsü, İstanbul, Yüksek Lisans Tezi, 158 s (yayımlanmamış).

Li, L., Maier, H. R., Partington, D., Lambert, M. F., Simmons, C.T., 2014. Performance assessment and improvement of recursive digital baseflow filters for cathoments with different physical charactersitics and hydrological inputs. Environmental Modelling and Software, 54, 3952.

Lyne, V., Hollick, M., 1979. Stochastic time-variable rainfall-runoff modelling. Institute of Engineers Australia National Conference. Publ. 79/10, 8993.

MGM, 2015. Meteoroloji Genel Müdürlüğü, Türkiye. https://www.mgm.gov.tr/veridegerlendirme/ il-ve-ilceler-istatistik.aspx?k=A， son erişim 29.03.2015.

Nathan, R. J., McMahon, T. A., 1990. Evaluation of automated techniques for base flow and recession analyses. Water Resources Research, 26 (7), 1465-1786.

Öziş, Ü., Keloğlu, N., 1979. Stochastic analysis of Manavgat flows, Antalya. International Seminar on Karst Hydrogeology, Oymapinar 1979, Proceedings (Editor: Günay). 305-315.

Piggott A. R., Moin S., Southam, C., 2005. A revised approach to the UKIH method for the calculation of baseflow. Hydrological Sciences Journal, 50 (5), 911-9203.

Saplığlu, K., 2005. Akarsu çekilmelerine etkiyen parametrelerin belirlenmesi ve çekilmenin modellenmesi. Süleyman Demirel Üniversitesi Fen Bilimleri Enstitüsü, Isparta, Yüksek Lisans Tezi, $72 \mathrm{~s}$ (yayımlanmamış).

Saplığlu, K., Çimen, M., 2010. Taban akışı ayrımı için yeni bir yöntem. e-Journal of New World Sciences Academy, Engineering Sciences, 1A0108, 5(4), 580-589.

Su, C.-H., Costelloe, J. F., Peterson, T. J., Western A. W., 2016. On the structural limitations of recursive digital filters for base flow estimation. Water Resources Research, 52, 4745-4764.

Szilagyi, J., Parlange B. M., 1998. Baseflow separation based on analytical solutions of the Boussinesq equation. Journal of Hydrology, 204, 251-260.

Ünal, E., 1981. Karst bölgelerindeki baraj haznelerinin yeraltı biriktirme hacminin Oymapınar örneğinde alçalma hidrografı yöntemiyle incelenmesi. Ege Üniversitesi İnşaat Fakültesi, İzmir, Yüksek Lisans Tezi, $68 \mathrm{~s}$ (yayımlanmamış).

Wittenberg, H., 1999. Baseflow recession and recharge as nonlinear storage processes. Hydrological Processes, 13, 715-726.

Wittenberg, H., Aksoy, H., 2010. Groundwater intrusion into leaky sewer systems. Water Science and Technology, 62 (1), 92-98.

Wittenberg H., 2003. Effects of season and man-made changes on baseflow and flow recession: case studies. Hydrological Processes, 17, 2113-2123.

Wittenberg H., Sivapalan, M., 1999. Watershed groundwater balance estimation using streamflow recession analysis and baseflow separation. Journal of Hydrology, 219, 20-33.

Zaifoğlu, H., 2013. Fırat akarsu havzası için topoğrafik ve hidrometeorolojik veriye dayanan taban akışı ayırma modeli. İstanbul Teknik Üniversitesi Fen Bilimleri Enstitüsü, İstanbul, Yüksek Lisans Tezi, $97 \mathrm{~s}$ (yayımlanmamış). 
